\title{
Diurnal nonmigrating tides in the tropical lower thermosphere
}

\author{
Jeffrey M. Forbes ${ }^{1}$, Maura E. Hagan², Saburo Miyahara ${ }^{3}$, Yasunobu Miyoshi ${ }^{3}$, and Xiaoli Zhang ${ }^{1}$ \\ ${ }^{1}$ Department of Aerospace Engineering Sciences, University of Colorado Boulder, CO 80309-0429, USA \\ ${ }^{2}$ High Altitude Observatory, National Center for Atmospheric Research, P.O. Box 3000, Boulder, CO 80307, USA \\ ${ }^{3}$ Department of Earth and Planetary Sciences, Kyushu University, 6-10-1 Hakozaki, 812-8581 Fukuoka, Japan
}

(Received January 9, 2003; Revised June 11, 2003; Accepted June 28, 2003)

\begin{abstract}
A comparison is performed between monthly-mean nonmigrating diurnal tide wind components at $95 \mathrm{~km}$ derived from Upper Atmosphere Research Satellite (UARS) wind observations, the Middle Atmosphere Circulation Model at Kyushu University (MACMKU), and the Global Scale Wave Model (GSWM) driven by latent heating due to deep tropical convection. A degree of overall agreement is obtained in the sense that annual-mean spectra at $95 \mathrm{~km}$ indicate that the UARS data, MACMKU and GSWM all share the same nonmigrating tide components (eastward-propagating with zonal wavenumber $s=-3$; westward-propagating with $s=2$; standing or zonallysymmetric with $s=0$; DE3, DW2, D0) at about the same power level. In combination with the migrating tide these wave components give rise to significant longitude variability in the total diurnal tidal fields. Beyond the above model/measurement agreements, significant discrepancies remain between the latitudinal-seasonal structures delineated by models and observation. For MACMKU, some of these discrepancies may be related to the specifics of the convective parameterization that is employed. Significant work remains to better delineate tropospheric forcing mechanisms and nonlinear wave-wave interactions as sources for nonmigrating tides.
\end{abstract}

Key words: Tides, nonmigrating, thermosphere, tropics.

\section{Introduction}

The absorption of solar radiation by the ground and the atmosphere give rise to the class of atmospheric oscillations referred to as solar thermal tides, with periods at subharmonics of a solar day (i.e., 24 hours, 12 hours, 8 hours, etc.). The zonally symmetric component of released heat gives rise to longitude-independent atmospheric oscillations that 'migrate' with the apparent motion of the sun to a ground-based observer. These sun-synchronous oscillations are referred to as migrating tides. Any zonal asymmetries (i.e., topography, land-sea differences, longitude dependences in absorbing species) that are introduced into the thermotidal excitation process give rise to the so-called nonmigrating tidal oscillations with zonal phase speeds (positive eastwards) given by

$$
C_{p h}=-\frac{n}{s} \Omega
$$

where $n=1$ and 2 for diurnal and semidiurnal oscillations, respectively, $\Omega=$ the rotation rate of the earth, and $s$ is the zonal wavenumber. In this notation eastward (westward) propagation corresponds to $s<0(s>0)$. Thus, the total tidal response may be viewed as the superposition of waves moving (with respect to the ground) faster than the sun, with the sun, and in the opposite direction of the sun (Chapman and Lindzen, 1970).

The existence of nonmigrating tidal oscillations in the atmosphere has been know for some time. For instance, their presence in diurnal and semidiurnal surface pressure variations was noted by Haurwitz $(1956,1965)$ and in many other

Copy right (C) The Society of Geomagnetism and Earth, Planetary and Space Sciences (SGEPSS); The Seismological Society of Japan; The Volcanological Society of Japan; The Geodetic Society of Japan; The Japanese Society for Planetary Sciences. subsequent works including analyses of GCM outputs (i.e., Tokioka and Yagai, 1987; Yagai, 1989). Subsequent numerical modeling efforts noted the probable importance of nonmigrating tides to the dynamics of the mesosphere and lower thermosphere (i.e., Forbes and Groves, 1987; Williams and Avery, 1996; Kattatov et al., 1996; Ekanayake et al., 1997; Miyahara et al., 1993, 1999; Miyahara and Miyoshi, 1997) consistent with contemporaneous analyses of satellite measurements (i.e., Lieberman, 1991; Hagan et al., 1997; Talaat and Lieberman, 1999). This general conclusion is now supported more definitively by a number of very recent model results (i.e., Hagan and Roble, 2001; Hagan and Forbes, 2002; Forbes et al., 2001; Angelats i Coll and Forbes, 2002; Grieger et al., 2002; Yamashita et al., 2002) and satellite data analyses (i.e., Angelats i Coll and Forbes, 2002; Forbes et al., 2002; Manson et al., 2003; Oberheide et al., 2002).

In the recent work of Forbes et al. (2002), horizontal wind measurements from the HRDI and WINDII instruments on the Upper Atmosphere Research Satellite (UARS) are analyzed to reveal the monthly climatological structures of nonmigrating diurnal tides. Due to viewing geometry and sampling restrictions, their analysis is confined to $\pm 40^{\circ}$ latitude and an altitude of $95 \mathrm{~km}$. The fields presented by Forbes et al. (2002) represent climatological averages over the period December 1991-September 1994 and 2-monthly means centered on the 15th of each month. Their results show that the most prominent nonmigrating diurnal tidal components at $95 \mathrm{~km}$ are the eastward-propagating diurnal tide with zonal wavenumber $s=-3$ (DE3), the standing or zonally-symmetric $(s=0)$ diurnal oscillation (D0), and the westward-propagating diurnal tide with $s=2$ (DW2). The strongest DE3 occurs primarily during Northern Hemi- 
Diurnal Tide Velocity Expansion Functions
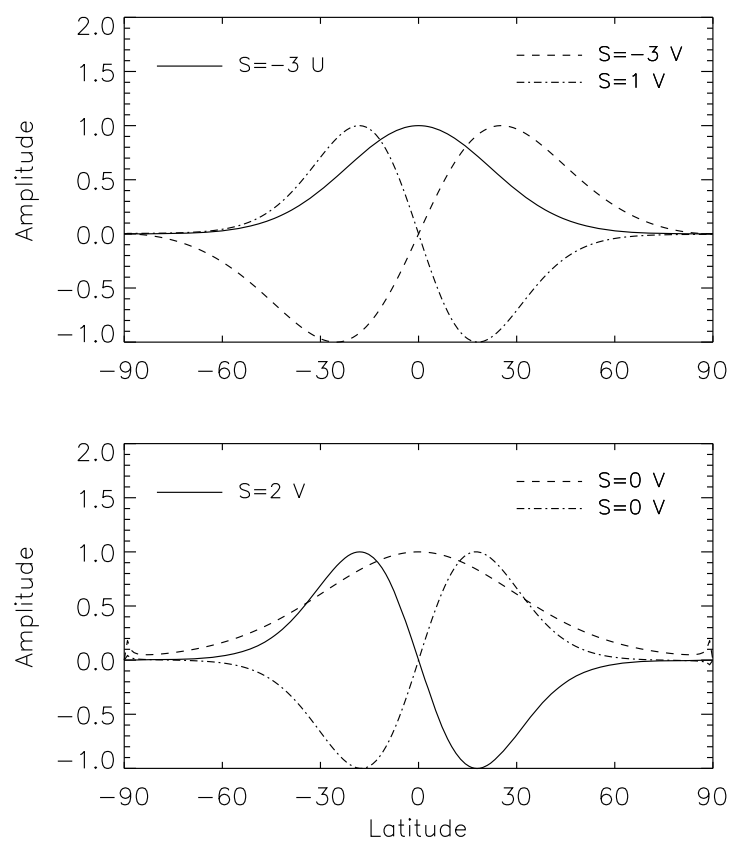

Fig. 1. Velocity expansion functions for selected Hough modes in Table 1. Top: Eastward (solid line) and northward (dashed line) expansion functions for first symmetric mode of DE3, and northward expansion function for DW1 (dash-dot line). Bottom: Northward expansion functions for first symmetric mode of DW2 (solid line) and first antisymmetric (dashed line) and symmetric (dash-dot line) modes of D0, respectively.

sphere summer/fall with maximum eastward winds near the equator of order $15 \mathrm{~ms}^{-1}$, and appears to be the vertical extension of the $s=3$ Kelvin wave (see also Talaat and Lieberman, 1999). The first antisymmetric mode of DE3 dominates during October-April, with maximum meridional winds near the equator of order $8 \mathrm{~ms}^{-1}$. D0 exists during nearly all months, and is nonsymmetric about the equator with maximum northward wind amplitudes in the Southern Hemisphere of order 7-10 $\mathrm{ms}^{-1}$. DW2 closely resembles the first symmetric propagating mode from classical tidal theory, with maximum northward wind amplitudes of order 10$12 \mathrm{~ms}^{-1}$ during September through February. The combination of DE3, D0 and DW2 with DW1 gives rise to significant longitude variations in the diurnal tide that varies from month to month.

Using heating rates from the NCEP/NCAR Reanalysis Project, Forbes et al. (2001) show that excitation of DE3 (vertical wavelength $\approx 56 \mathrm{~km}$ ) by convective and condensation heating in the tropics is far more important than excitation by boundary layer processes or insolation absorption by $\mathrm{H}_{2} \mathrm{O}$. Within the tropics, topography primarily projects onto zonal wavenumbers $s=1,3$ and 4, whereas land-sea difference patterns project onto wavenumbers 2, 3 and 4 (Yagai, 1989). DE3 arises due to interaction of solar radiation with the $s=4$ surface zonal component at low latitudes (Yagai, 1989); the complementary DW5 oscillation does not reach the lower thermosphere to any significant degree due to its relatively short vertical wavelength (Forbes et al., 2002). A similar situation exists for the pairs (D0, DW2), (DE1, DW3) and (DE2, DW4) connected with the $s=1,2$ and 3 components, respectively, of topography and land-sea difference at low latitudes. Like DE3, DE2, DE1, DW2 and D0 possess sufficiently long vertical wavelengths ( $\geq 25 \mathrm{~km}$ ) to allow propagation to the lower thermosphere. Although DE1 and DE2 do not appear as prominently in the UARS wind analysis of Forbes et al. (2002) as DE3, DW2 and D0, they do constitute an important component of the lower thermosphere response of the Kyushu University General Circulation Model to be described below (cf. Ekanayake et al., 1997). In addition, Hagan and Roble (2001) show that nonlinear interaction between the migrating diurnal tide and the stationary planetary wave with $s=1$ in the stratosphere and mesosphere also generates DW2 and D0 oscillations that reach significant amplitudes at $95 \mathrm{~km}$. Here the modulation of DW1 that generates these sidebands in wavenumber space is analogous to the topographic mechanism, except the $s=1$ modulation acts on the wave field instead of on the wave source. Hereafter, we will distinguish these sources as 'tropospheric' and 'middle atmospheric', respectively.

The Forbes et al. (2002) study did not include any model comparisons to interpret the observational results and to evaluate our understanding of the physics and the status of modeling capability. With these goals in mind, herein we compare the Forbes et al. (2002) climatological fields with those derived from the Middle Atmosphere Circulation Model at Kyushu University (MACMKU; Miyahara et al., 1993, 1999; Miyahara and Miyoshi, 1997) and the Global Scale Wave Model (GSWM; Hagan, 1996; Hagan et al., 1995, 1999). MACMKU is a general circulation model extending up to about $140 \mathrm{~km}$ with complete tropospheric physics and diurnal cycle throughout the model domain. In principle, the MACMKU is thus capable of addressing both the tropospheric and middle atmospheric mechanisms for generating the $s=0$ and $s=2$ wave components, as noted above. The GSWM, on the other hand, provides steady-state linearized solutions to the perturbation dynamical equations for specified periodic forcing with a particular period and zonal wavenumber. The GSWM results depicted in the present work (Hagan and Forbes, 2002) utilized forcing due to latent heat release connected with deep tropical convection, as derived from global cloud imagery in the manner described in Forbes et al. (1997) and Hagan and Forbes (2002). The GSWM thus only accounts for the tropospheric component of forcing for nonmigrating diurnal tides, but includes an observational basis for the prescribed excitation.

\section{Hough Modes}

In anticipation of forthcoming results, we now review the primary horizontal and vertical structures of several diurnal wave components that reveal themselves in the data. Table 1 lists the relevant diurnal Hough modes including approximate vertical wavelengths calculated for an isothermal temperature of $256 \mathrm{~K}$. Velocity expansion functions corresponding to the asterisked modes are plotted in Fig. 1. The reader is reminded of the symmetry convention for Hough functions and velocity expansion functions of classical tidal theory (e.g., Chapman and Lindzen, 1970), the amplitude distributions of which are all mirror images of each other between N. and S. Hemispheres. A mode is referred to as symmetric (antisymmetric) if the Hough function (representing the temperature, density and pressure distributions) and 
Table 1. Vertical wavelengths of various tidal modes referenced in the text, corresponding to an isothermal atmosphere of $256 \mathrm{~K}$.

\begin{tabular}{|c|c|c|c|c|c|}
\hline$s$ & Propagation direction & Notation & Symmetric/Antisymmetric & Meridional index & Vertical wavelength \\
\hline \multirow[t]{2}{*}{-3} & eastward & DE3 & $\mathrm{S}^{*}$ & 3 & 56 \\
\hline & & & $A^{*}$ & 4 & 30 \\
\hline \multirow[t]{2}{*}{0} & standing & D0 & $A^{*}$ & 1 & 102 \\
\hline & & & $\mathrm{S}^{*}$ & 2 & 27 \\
\hline \multirow[t]{2}{*}{2} & westward & DW2 & $\mathrm{S}^{*}$ & 2 & 27 \\
\hline & & & A & 3 & 16 \\
\hline \multirow[t]{2}{*}{1} & westward & DW1 & $\mathrm{S}^{*}$ & 1 & 28 \\
\hline & & & A & 2 & 16 \\
\hline
\end{tabular}

Annual Mean Diurnal Nonmigrating lidal Winds at $95 \mathrm{~km}$
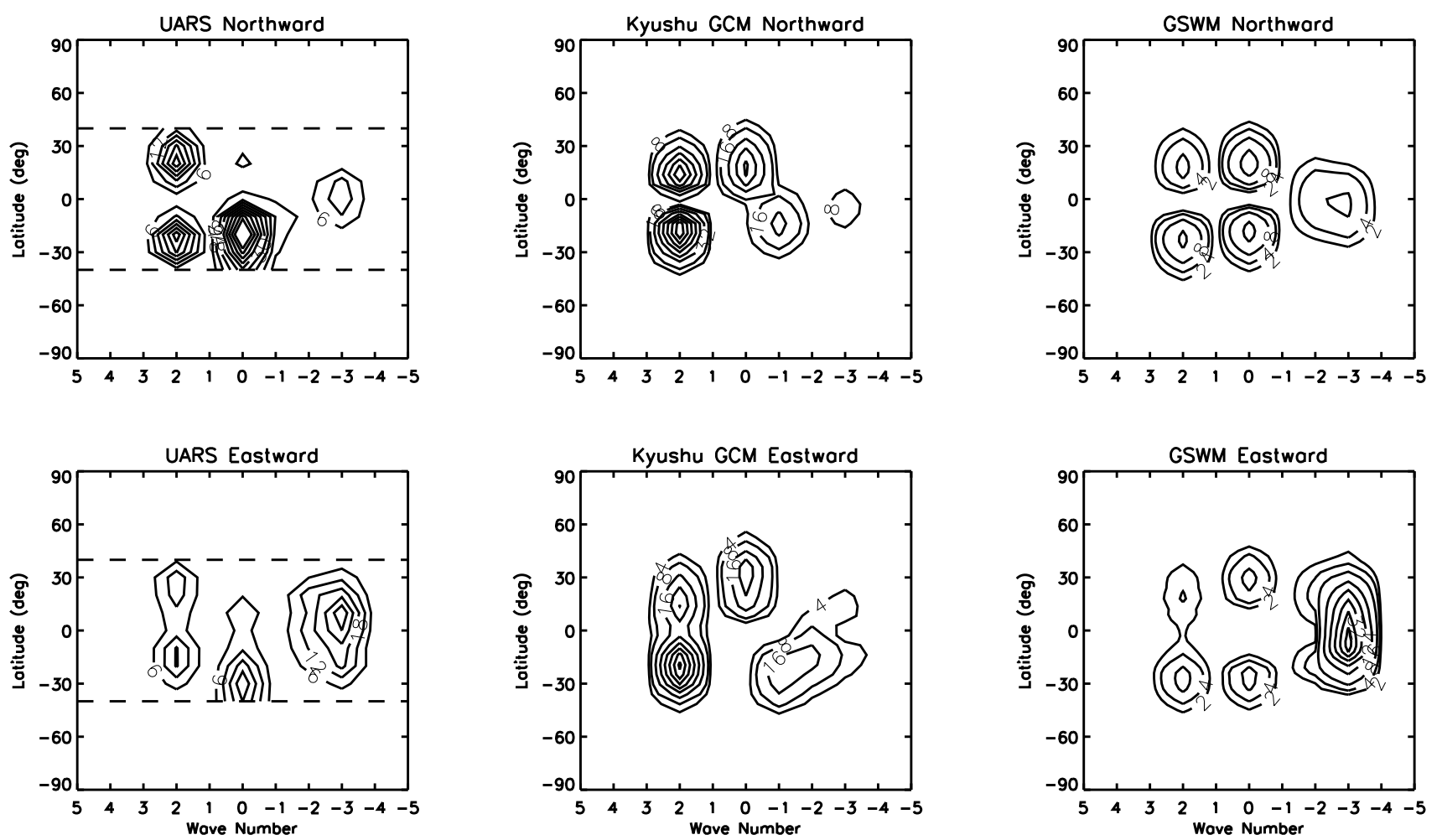

Fig. 2. Zonal wavenumber power spectra as a function of latitude for annual-mean diurnal nonmigrating tidal winds at $95 \mathrm{~km}$. Top: northward wind component. Bottom: Eastward wind component. Left: UARS data analyses (Forbes et al., 2002). Middle: Middle Atmosphere Circulation Model at Kyushu University (MACMKU; Miyahara et al., 1993, 1999; Miyahara and Miyoshi, 1997). Right: Global Scale Wave Model (Hagan and Forbes, 2002). Positive wavenumbers correspond to westward propagation. Contours in $\mathrm{m}^{2} \mathrm{~s}^{-2}$.

eastward wind velocity function are in phase (anti-phase) between hemispheres. Further, for all symmetric (antisymmetric) modes the northward wind velocity function is in antiphase (phase) between hemispheres.

One wave depicted in Fig. 1 is the first symmetric mode of DW2, which bears considerable resemblance to the betterknown first symmetric mode of DW1. The northward wind distribution for this mode has maxima at $\pm 18^{\circ}$ latitude and nodes at the equator and poles, with a $180^{\circ}$ (12-hour) phase shift between hemispheres. For a $256 \mathrm{~K}$ isothermal atmosphere, the vertical wavelength calculated in accord with Laplace's tidal equation is $25 \mathrm{~km}$.

A second prominent diurnal oscillation to be discussed below is the Kelvin wave with $s=-3$. A Kelvin wave is the gravest symmetric eastward-propagating gravity-type mode for a given zonal wavenumber. According to the theory of linearized oscillations on a rotating sphere (LonguetHiggins, 1968), the northward wind magnitude for a Kelvin wave is small compared to the eastward wind component. The eastward wind distribution is Gaussian-shaped about the equator with full-width at half-maximum of $52^{\circ}$ latitude (see Fig. 1); the phase difference between hemispheres is $0^{\circ}$. The isothermal vertical wavelength for this oscillation is $56 \mathrm{~km}$. The eastward wind distribution for the first antisymmetric mode is similar in shape to the northward wind distribution for DW1 (Fig. 1).

Figure 1 shows two wave modes associated with D0. The fundamental (gravest) mode is antisymmetric, so that the northward wind maximizes at $0^{\circ}$ latitude and is symmetric about the equator in both amplitude and phase. The am- 

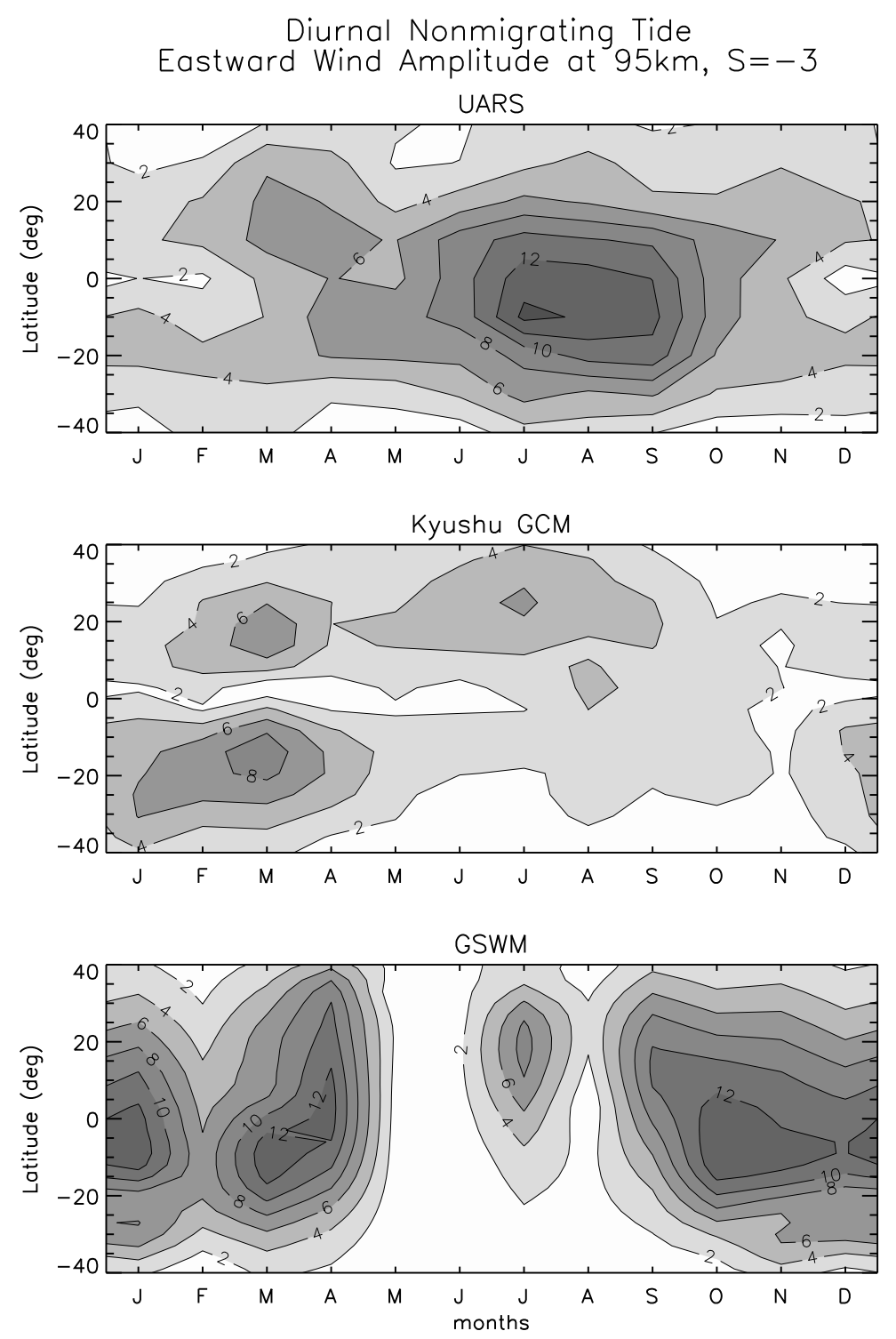

Fig. 3. Latitude-height contours of eastward wind amplitude for DE3. Top: UARS data analyses (Forbes et al., 2002). Middle: Middle Atmosphere Circulation Model at Kyushu University (MACMKU; Miyahara et al., 1993, 1999; Miyahara and Miyoshi, 1997). Bottom: Global Scale Wave Model (Hagan and Forbes, 2002). Contours in $\mathrm{ms}^{-1}$.

plitude full-width at half maximum is $72^{\circ}$, and the associated vertical wavelength is $102 \mathrm{~km}$. The eastward wind component has nodes at the equator and poles, with maxima at $\pm 29^{\circ}$ latitude, and a 12-hour phase shift between hemispheres. The second mode of D0 is symmetric. The northward wind has maxima at $\pm 18^{\circ}$ latitude, nodes at the equator and poles, and 12-hour phase shift between hemispheres. The eastward wind is symmetric about the equator, with maxima at $\pm 25^{\circ}$ latitude. The symmetric mode has a vertical wavelength of $27 \mathrm{~km}$. Note that the structure of the first symmetric mode of D0 is very similar to that of DW1 and DW2, making it difficult to distinguish between these oscillations without complete sampling in longitude and local time.

\section{Results}

\subsection{Overview: annual mean power spectra}

A broad perspective on our results is provided in Fig. 2, which illustrates annual-mean zonal wavenumber spectra at diurnal frequency corresponding to UARS data, MACMKU and GSWM. In order to emphasize the nonmigrating tidal oscillations, the migrating $(s=1)$ component was removed prior to construction of the power spectrum (see Forbes et al., 2002, for details). It is immediately apparent in Fig. 2 that the data and models share a common feature: all three indicate the spectral energy to be concentrated around the westward $s=2$ component, the standing $s=0$ oscillation, and eastward-propagating waves in the zonal wavenumber range $s=-1$ to $s=-3$. For UARS and GSWM, spectral energy in the eastward range is maximum at $s=-3$ with significant energy at $s=-2$ and comparatively negligible amounts at $s=-1$. MACMKU indicates maximum eastward energy at $s=-1$, tailing off towards $s=-3$. For $s=0$, the UARS data indicate a strong asymmetry, with power maxima in the $\mathrm{S}$. Hemisphere. In contrast, the MACMKU indicates a N. Hemisphere maximum for $s=0$, whereas the GSWM depicts a more symmetric distribution. All three sources depict a symmetric distribution for the $s=2$ northward wind 

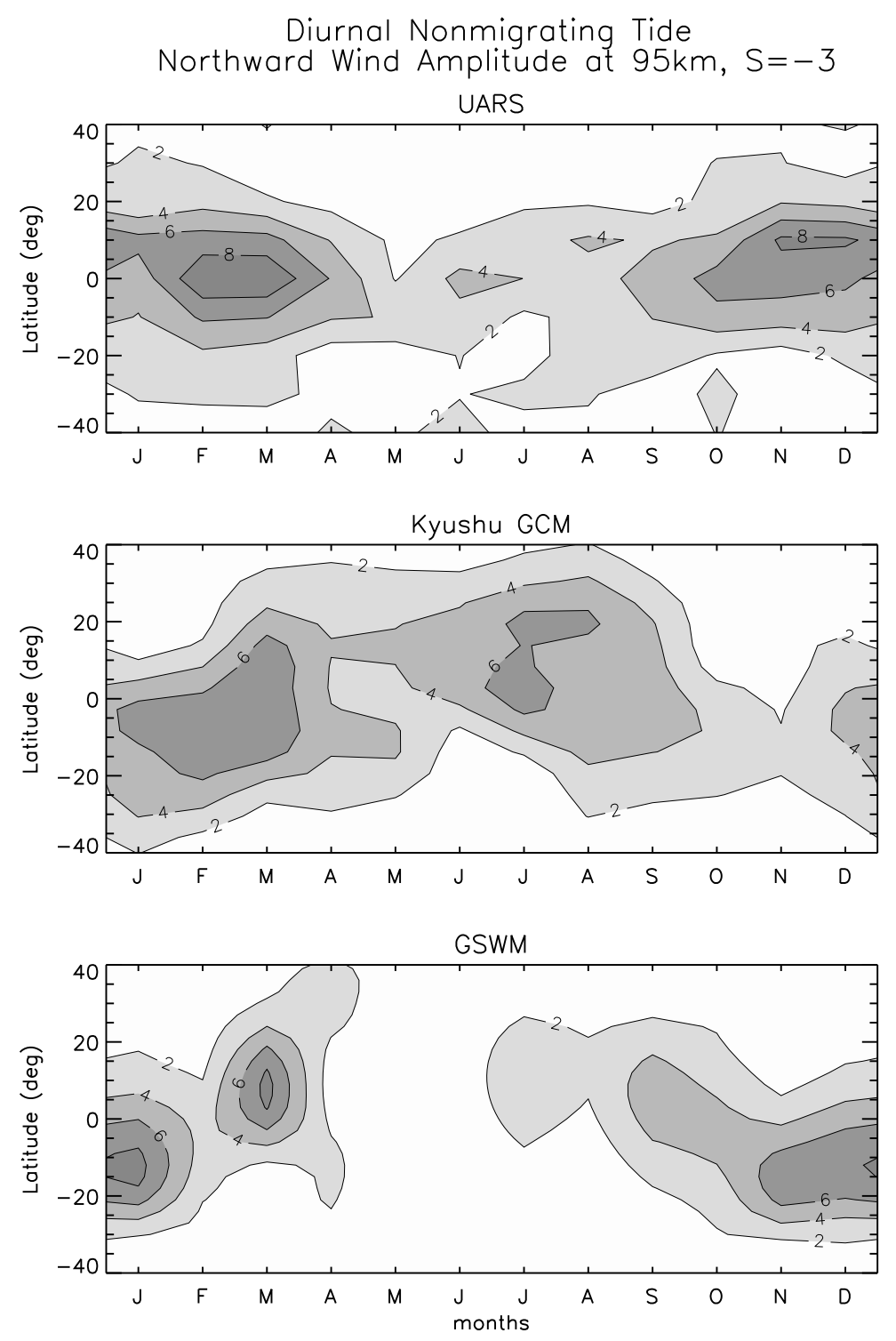

Fig. 4. Same as Fig. 3, except for northward wind amplitude of DE3.

component, and larger energy in the S. Hemisphere for the eastward wind.

The multi-year annual mean climatology of spectral energy in Fig. 2 depicts broad agreement between observations and models: Similar-amplitude energies distributed similarly in wavenumber space. As noted by Forbes et al. (2002), D0 and DW2 originate from two sources: (1) latent (convective/condensation) heating in the troposphere (Forbes et al., 2001); and (2) nonlinear coupling between the SPW with $s=1$, and the migrating $(s=1)$ diurnal tide (Hagan and Roble, 2001). MACMKU attempts to address all the physics necessary to account for the presence of both mechanisms, whereas the GSWM only models the response to tropospheric latent heating. However, it must be emphasized that the manner in which convection (and perhaps other proceses) is parameterized in MACMKU is not unique, and that other physics-based parameterizations would likely lead to a different spectrum of nonmigrating tides being generated.

In the following, we now examine latitude vs. month climatologies of the same wave components at $95 \mathrm{~km}$.

\subsection{The $s=-3$ eastward-propagating diurnal tide (DE3)}

In a latitude-month contour format, Figure 3 compares the eastward wind component of DE3 at $95 \mathrm{~km}$ between UARS, MACMKU and GSWM. The UARS data indicate maximum amplitudes $\left(\sim 6-14 \mathrm{~ms}^{-1}\right)$ during N. Hemisphere summer and fall, quasi-symmetrically distributed about the equator with latitudinal width similar to that of the first symmetric mode (i.e., 'Kelvin wave') of DE3. During the remaining months, UARS indicates maxima $\left(\sim 4 \mathrm{~ms}^{-1}\right)$ just equatorward of $\pm 20^{\circ}$ latitude, consistent with presence of the first antisymmetric mode of DE3. Similar antisymmetric structures are seen in MACMKU, with amplitudes as large as 6-8 $\mathrm{ms}^{-1}$. This antisymmetric tendency continues through June for MACMKU, tending more towards a symmetric distribution during July-October, but with much smaller amplitudes $\left(2-4 \mathrm{~ms}^{-1}\right)$ than UARS. GSWM results in the lower panel indicate similar amplitudes as UARS; however, the latitude-month distributions throughout the year are much different than the observations. The GSWM indicates max- 

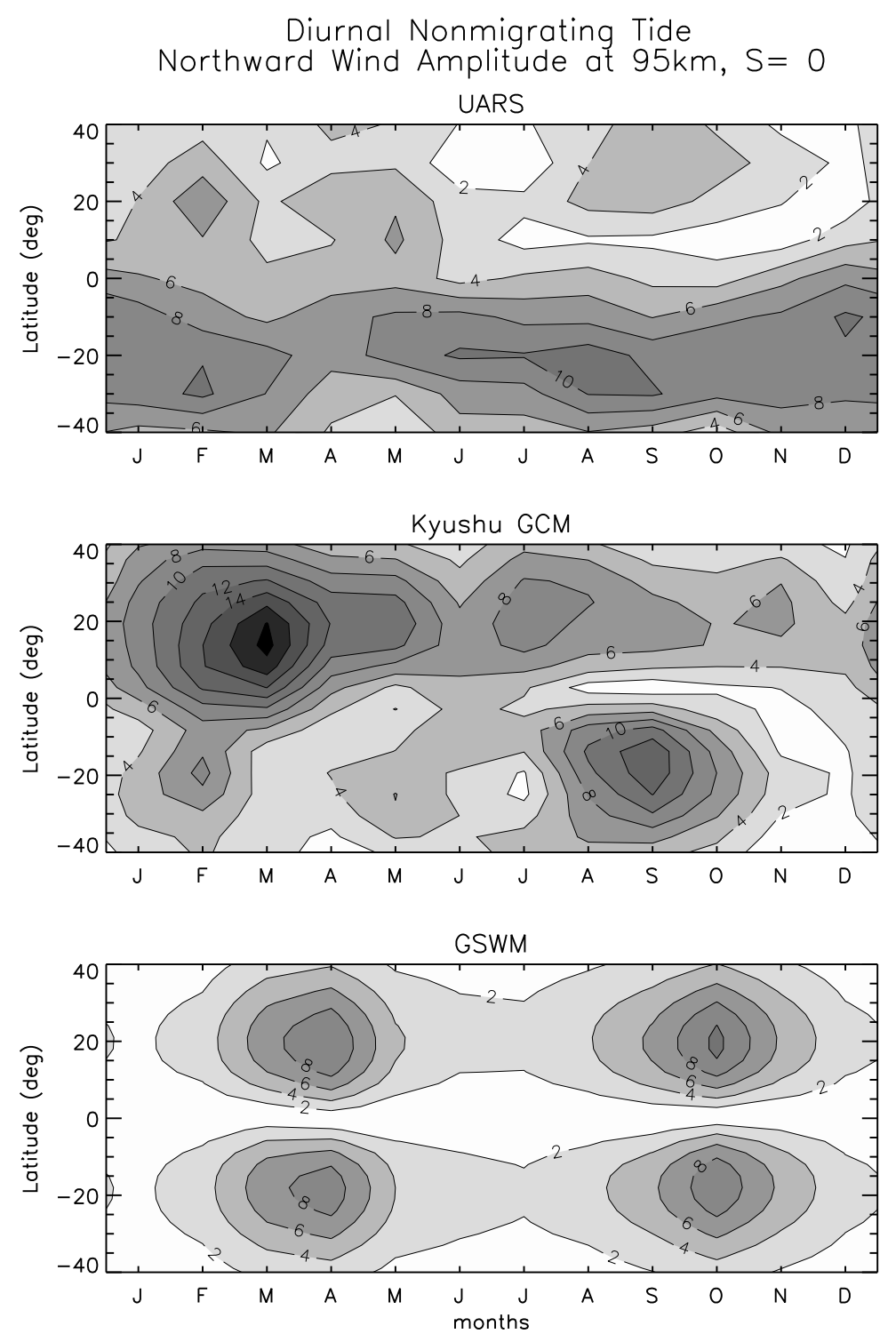

Fig. 5. Same as Fig. 3, except for northward wind amplitude of D0.

imum amplitudes (also quasi-symmetric about the equator with full-width of $\sim 50^{\circ}-60^{\circ}$ latitude) during non-summer months, just opposite to the observations. Additional calculations with the GSWM (not shown) indicate that the seasonal-latitudinal structure of DE3 is strongly influenced by the zonal mean wind distribution; this may be one source of discrepancy between the GSWM and the UARS data. Errors in modeled tropospheric wave sources may also be responsible.

Figure 4 illustrates the northward wind amplitudes for DE3 in the same format as Fig. 3. The measurements are primarily characterized by wind maxima at low latitudes, reaching values of $\sim 8 \mathrm{~ms}^{-1}$ between October and April, and $\sim 2-4 \mathrm{~ms}^{-1}$ during N. Hemisphere summer. This behavior manifests presence of the first symmetric and antisymmetric modes of DE3, as in the eastward wind component. Behavior of MACMKU bears considerable similarity to the UARS data in Fig. 4, except that the pattern shifts $\sim 10^{\circ}$ south of the equator during winter, and $\sim 10^{\circ}$ north of the equator during summer. The GSWM also tends to follow that of
MACMKU, roughly following the path of the ITCZ during the course of the year.

\subsection{The standing or zonally-symmetric $(s=0)$ diurnal tide (D0)}

Figure 5 depicts the northward wind amplitude for D0. A common feature between the observations and models is the tendency for small values in the equatorial region, with maxima tending to occur between $15^{\circ}-30^{\circ}$ latitude in one or both hemispheres. A similar tendency is seen in the eastward wind component (not shown).

According to the UARS data, D0 is present at similar amplitudes throughout the year, with maximum values $(\sim 6-$ $10 \mathrm{~ms}^{-1}$ ) in the S. Hemisphere. During February, May and August-October, maxima near $\pm 20-30^{\circ}$ latitude are evident, indicating presence of the first symmetric component of D0 in addition to the first antisymmetric mode (which is the gravest mode for $s=0$ ). The MACMKU similarly indicates primarily asymmetric behavior, however, with maximum values in the N. Hemisphere during the first half of the year. During August and October, a more symmetric distri- 

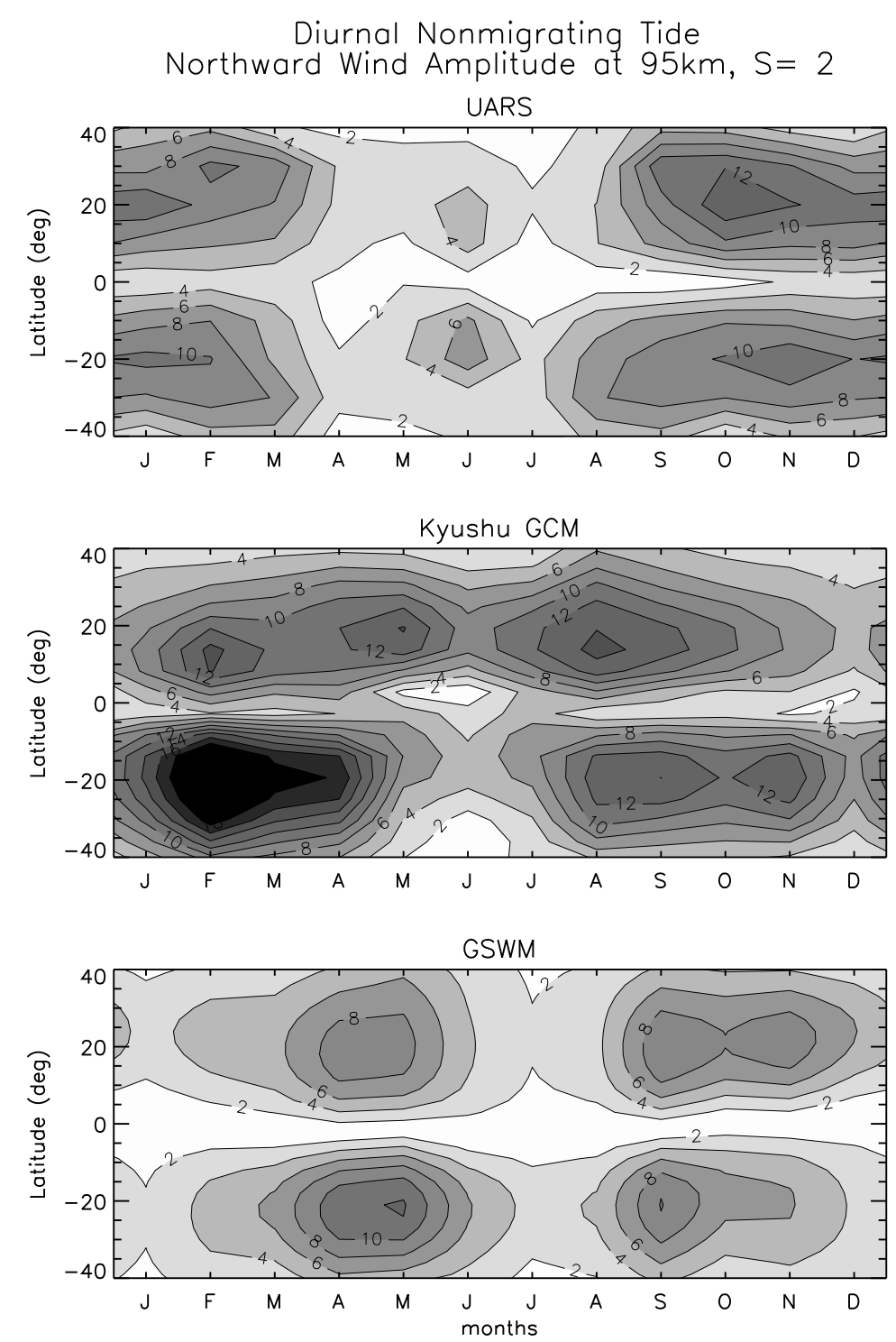

Fig. 6. Same as Fig. 3, except for northward wind amplitude of DW2.

bution prevails, whereas in September maximum values are found in the S. Hemisphere.

The GSWM amplitude distribution is symmetric throughout the year with distinct maxima near April and October where dissipation in the GSWM is minimum. Note that the Doppler-shifting effects of the zonal mean wind are absent For D0. However, potentially important effects of zonal mean vorticity (McLandress, 2002) are retained in the equations. The GSWM indicates dominance of the first symmetric mode of D0. It should be mentioned that this mode is more efficiently excited than the first antisymmetric mode, since the vertical wavelength of the latter is much greater than the depth of the excitation region (ca. $15 \mathrm{~km}$ ).

3.4 The westward-propagating diurnal tide with $s=2$ (DW2)

The northward wind amplitude distributions for DW2 are indicated in Fig. 6. For both models and data, the horizontal structures conform closely to that of the first symmetric (gravest) mode of DW2, with vertical wavelength of order $27 \mathrm{~km}$. The next mode of DW2 has vertical wavelength of $16 \mathrm{~km}$, and therefore does no efficiently propagate to $95 \mathrm{~km}$.
The models and data all exhibit similar maximum amplitudes of order $8-14 \mathrm{~ms}^{-1}$. The UARS data indicate nearsuppression of this oscillation during April-May and July, whereas minima are seen in MACMKU during June and December. For the GSWM, suppression of the oscillation tends to occur during the non-equinoctial months of DecemberFebruary and July-August.

\section{Summary and Conclusions}

Monthly climatologies of the eastward and northward wind components corresponding to nonmigrating diurnal tides have recently been published by Forbes et al. (2002). They show that the most prominent wave components are the eastward-propagating diurnal tide with zonal wavenumber $s=-3$ (DE3), the standing $(s=0)$ diurnal oscillation (D0), and the westward-propagating diurnal tide with $s=2$ (DW2). According to Forbes et al. (2001) DE3 is primarily excited by latent heating associated with deep tropical convection. D0 and DW2 are also excited by latent heating, but can also be excited by nonlinear interaction between the diurnal migrating tide (DW1), and the stationary planetary 
wave with $s=1$ (Hagan and Roble, 2001). In the present study, we have sought to ascertain our current understanding of and capability to simulate these diurnal wave components, by comparing the UARS results with MACMKU and the GSWM. MACMKU is a middle atmosphere general circulation model that includes realistic tropospheric physics including a diurnal cycle, convective heating, topographic effects, etc., as well as nonlinear wave-wave interactions. The GSWM is a steady-state model with latent heat forcing of nonmigrating tides based upon rainfall rates derived from global satellite measurements.

Our conclusions are as follows:

- Annual-mean spectra at $95 \mathrm{~km}$ indicate that the UARS data, MACMKU and GSWM all share the same nonmigrating tide components (DE3, DW2, D0) at about the same power level. In addition, MACMKU reflects significant power at DE1 and DE2.

- MACMKU, UARS data, and the GSWM all yield similar-magnitude $\left(\sim 5-15 \mathrm{~ms}^{-1}\right) s=0,2,-3 \mathrm{com}-$ ponents at $95 \mathrm{~km}$. In combination with the migrating tide these wave components give rise to significant longitude variability in the total diurnal tidal fields (Forbes et al., 2002).

- Beyond the above model/measurement agreements, significant discrepancies remain between the latitudinalseasonal structures delineated by models and observation. For MACMKU, some of these discrepancies may be related to the specifics of the convective parameterization that is employed.

- Further investigations are required to better establish the forcing mechanisms and the global implications of nonmigrating tides (i.e., thermospheric effects, emissions, ionospheric dynamo, etc.)

- The TIMED/Ground-Based Program will provide new opportunities to identify and understand cause-effect relationships affecting wind, momentum, temperature, thermal energy, and emission variations in the lower thermosphere.

Acknowledgments. This work was supported under NASA Grant NAG5-5028 and NSF Grant ATM-0097829 to the University of Colorado. The algorithm for solving Laplace's Tidal Equation and generating Table 1 and the curves in Fig. 1 was developed and kindly provided by Prof. Scott E. Palo.

\section{References}

Angelats i Coll, M. and J. M. Forbes, Nonlinear interactions in the upper atmosphere: The $s=1$ and $s=3$ nonmigrating semidiurnal tides, $J$. Geophys. Res., 107(A8), 1157, doi:10.1029/2001JA900179, 2002.

Chapman, S. and R. S. Lindzen, Atmospheric Tides: Thermal and Gravitational, 200 pp., Gordon and Breach, New York, 1970.

Ekanayake, E. M. P., T. Aso, and S. Miyahara, Background wind effect on propagation of nonmigrating diurnal tides in the middle atmosphere, $J$ Atmos. Solar-Terr. Phys., 59, 401-429, 1997.

Forbes, J. M. and G. V. Groves, Diurnal propagating tides in the low-latitude middle atmosphere, J. Atmos. Terr. Phys., 49, 153-164, 1987.

Forbes, J. M., M. E. Hagan, X. Zhang, and K. Hamilton, Upper atmosphere tidal oscillations due to latent heat release in the tropical troposphere, Ann. Geophys., 15, 1165-1175, 1997.

Forbes, J. M., X. Zhang, and M. E. Hagan, Simulations of diurnal tides due to tropospheric heating from the NCEP/NCAR Reanalysis Project Geophys. Res. Lett., 28, 3851-3854, 2001.

Forbes, J. M., X. Zhang, W. Ward, and E. R. Talaat, Nonmigrating diurnal tides in the thermosphere, J. Geophys. Res., 107(D23), 4322, doi:10.1029/2001JD001232, 2002.

Grieger, N. et al., General circulation model results on migrating and nonmigrating tides in the mesosphere and lower thermosphere. Part I: Comparison with observations, J. Atmos. Solar-Terr. Phys, 897-911, 2002.

Hagan, M. E., Comparative effects of migrating solar sources on tidal signatures in the middle and upper atmosphere, J. Geophys. Res., 101, 21,21321,222, 1996.

Hagan, M. E. and J. M. Forbes, Migrating and nonmigrating diurnal tides in the middle and upper atmosphere excited by tropospheric latent heat release, J. Geophys. Res., 107(D24), 4754, doi:10.1029/2001JD001236, 2002 .

Hagan, M. E. and R. G. Roble, Modeling diurnal tidal variability with the NCAR TIME-GCM, J. Geophys. Res., 106, 24869-24882, 2001.

Hagan, M. E., J. M. Forbes, and F. Vial, On modeling migrating solar tides, Geophys. Res. Lett., 22(8), 893-896, 1995.

Hagan, M. E., C. McLandress, and J. M. Forbes, Diurnal tidal variability in the upper mesosphere and lower thermosphere, Ann. Geophys., 15, 11761186, 1997.

Hagan, M. E., M. D. Burrage, J. M. Forbes, J. Hackney, W. J. Randel, and X. Zhang, GSWM-98: Results for migrating solar tides, J. Geophys. Res. 104, 6813-6827, 1999.

Haurwitz, B., The geographical distribution of the solar semidiurnal pressure oscillation, Meteorol. Pap., 2(5), New York University, 1956.

Haurwitz, B., The diurnal surface pressure oscillation, Archiv. Meteorol. Geophys. Biokl., A14, 361-379, 1965.

Kattatov, B. et al., Dynamics of the mesosphere and lower thermosphere as seen by MF radars and the high resolution Doppler imager/UARS, $J$ Geophys. Res., 101, 10393-10404, 1996.

Lieberman, R. S., Nonmigrating diurnal tides in the equatorial middle atmosphere, J. Atmos. Sci., 48, 1112-1123, 1991.

Longuet-Higgins, M. S., The eigenfunctions of Laplace's tidal equation over a sphere, Phil. Trans. Roy. Met. Soc. Lon., A262, 511-607, 1968.

Manson, A. H., Y. Luo, and C. Meek, Global distributions of diurnal and semidiurnal tides: Observations from HRDI-UARS of the MLT region, $J$ Geophys. Res., 2003 (in press).

McLandress, C., The seasonal variation of the propagating diurnal tide in the mesosphere and lower thermosphere. Part II: The role of tidal heating and zonal mean winds, J. Atmos. Sci., 59, 907-922, 2002.

Miyahara, S. and Y. Miyoshi, Migrating and nonmigrating atmospheric tides simulated by a middle atmosphere general circulation model, Adv. Space Res., 20, 1201-1207, 1997.

Miyahara, S., Y. Yoshida, and Y. Miyoshi, Dynamic coupling between the lower and upper atmosphere by tides and gravity waves, J. Atmos. Terr. Phys., 55, 1039-1053, 1993.

Miyahara, S., Y. Miyoshi, and K. Yamashita, Variations of migrating and nonmigrating tides simulated by the middle atmosphere circulation model at Kyushu University, Adv. Space Res., 24, 1549-1558, 1999.

Oberheide, J., M. E. Hagan, R. G. Roble, and D. Offermann, Sources of nonmigrating tides in the tropical middle atmosphere, J. Geophys. Res. 107(D21), 4567, doi:10.1029/2002JD002220, 2002.

Talaat, E. R. and R. S. Lieberman, Nonmigrating diurnal tides in mesospheric and lower thermospheric winds and temperatures, J. Atmos. Sci., 56, 4073-4087, 1999.

Tokioka, T. and I. Yagai, Atmospheric tides appearing in a global atmospheric general circulation model, J. Meteor. Soc. Japan, 65, 423-437, 1987.

Williams, C. R. and S. K. Avery, Diurnal nonmigrating tidal oscillations forced by deep convective clouds, J. Geophys. Res., 101, 4079-4091, 1996.

Yagai, I., Nonmigrating thermal tides detected in data analysis and a general circulation model simulation, J. Geophys. Res., 94, 6341-6356, 1989.

Yamashita, K., S. Miyahara, Y. Miyoshi, K. Kawano, and J. Ninomiya, Seasonal variation of non-migrating semidiurnal tide in the polar MLT region in a general circulation model, J. Atmos. Solar-Terr. Phys., 1083 1094, 2002.

J. Forbes (e-mail: forbes@colorado.edu), M. Hagan (e-mail: hagan@ ucar.edu), S. Miyahara (e-mail: sbm@geo.kyushu-u.ac.jp), Y. Miyoshi (e-mail: miyoshi@geo.kyushu-u.ac.jp), and X. Zhang (e-mail: zhangx@ rtt.colorado.edu) 